\title{
The Syntax and Pragmatics of Referring Expressions in Gichuka: A Challenge to the Generative Grammar's Logical Form in Assigning Meaning to Sentences ${ }^{1}$
}

\author{
Silvano Murithi Ndwiga \\ University of Nairobi \\ Department of Linguistics and Languages (Alumnus) \\ P.O Box 30197, 00100. \\ Nairobi, Kenya
}

\begin{abstract}
This study analyses the structure and assignment of truth conditional meaning of sentences containing referring $(R-)$ expressions in Gichuka, a Bantu language within the Niger-Congo family spoken by the Ameru people living on the North Eastern slopes of Mount Kenya. The study finds that the assignment of truth conditional meaning to sentences with $R$-expressions is not a purely syntactic matter but one that involves the interplay of syntax and pragmatics. It argues that the generative grammar's proposal that logical forms constrain all aspects of the truth conditional meaning in sentences is inadequate because it fails to account for pragmatic processes such as saturation and enrichment that derive propositional forms which bear truth conditions in sentences containing $R$-expressions. It makes a case for the thesis that contextual features play a significant role in assigning truth conditional meaning to sentences containing $R$-expressions, as expounded in the relevance theory.
\end{abstract}

Keywords: R-expressions, logical form, saturation and enrichment

\section{Introduction}

The study characterizes the relations that exist between Gichuka R-expressions and their predicates in terms of their morpho-syntactic, semantic and pragmatic properties. This characterization is important because in Chomsky's generative grammar, it is the relations that hold between predicates and their arguments or lexical NPs ${ }^{2}$ that determine the meaning of sentences through the mediation of the logical form (Chomsky, 1977). ${ }^{3}$ The logical form, according to Chomsky, is a level of representation that specifies the linguistic meaning of the sentences and it is uniform for all languages in the sense that "any thought expressible in human language is representable in it" (1995:21). Chomsky therefore equates logical forms to propositional forms (Ndwiga, 2014). The latter, according to the relevance-theoretic framework, are conceptual representations of complete thoughts and are fundamental bearers of truth conditions. This study aims to demonstrate the interface of syntax and pragmatics in assigning truth conditional meaning to sentences containing lexical NPs in Gichuka. In this study, the distinction between logical forms and propositional forms is clarified and the role of each of the two representations in assigning truth conditional meaning is demonstrated.

The study is based largely on the analysis of data this author collected for his $\mathrm{PhD}$ research, supplemented by secondary research. It is divided into three main sections: section 1 reviews the distribution of $\mathrm{R}$ - expressions in different sentence positions. Section 2 examines the assignment of the truth conditional meaning of R-expressions in different sentence patterns in Gichuka. Here, the gap between the syntactically constrained semantic representations and the meaning that phrases and sentences (containing $\mathrm{R}$-expressions) attain in actual speech situations is investigated. Section 3 presents a summary of the results.

\footnotetext{
${ }^{1}$ This paper is a revised version of chapter four of this Author's $\mathrm{PhD}$ thesis that was presented at the University of Nairobi, Kenya in November 2014. The chapter was titled 'Referring Expressions in Gichuka'.

${ }^{2}$ In this study, the terms 'R-expressions' and 'lexical NPs' are used interchangeably but strictly to refer to those lexical NPs that bear the feature matrix [— anaphor, - pronominal] (Chomsky 1995:41). Bound and free pronominal morphemes are therefore excluded from this definition given their feature matrix [+ pronominal]. These will be used in specific examples where they are necessary to demonstrate a relevant issue.

${ }^{3}$ Chomsky suggests that the meaning of a sentence is defined in terms of its truth conditions and that what the sentence describes corresponds with the actual state of affairs in the world. While admitting that there exists an intricate relationship between the grammar and other cognitive systems, he points out that the "grammar that comes into existence in the mind of the speaker will be intimately interwoven, at specific points, with other cognitive structures" (1977:37).
} 


\section{Distribution of $\mathrm{R}$-expressions in Gichuka sentences}

According to Chomsky (1995:41), an R-expression is a lexical NP that can pick a referent from the world of discourse without an antecedent within or outside its syntactic domain. It is referentially independent and bears the feature specification [-anaphor, - pronominal]. The number of $\mathrm{R}$-expressions and the positions they occupy in sentences is dependent on the morpho-syntactic features of predicates with which they occur in sentences, as can be seen in the following sections.

$1.1 \mathrm{R}$-expressions in equative clauses

In Gichuka, an equative clause has the copula verb $n i$ 'be'. The verb may appear either in a finite form ari or in an uninflected form $n i$, as can be seen in (1) and (2).

(1)

(2)
Mu-geni
NC1-visitor
$a-a-r-i$
3SG-tns-be-fv
n-omba
NC4-house

The visitor is in the house

$\begin{array}{lll}\text { Mugure } & n i & \text { mu-alimo } \\ \text { Mugure } & \text { be } & \text { NC1-teacher } \\ \text { Mugure is a teacher } & & \end{array}$

mu-alimo

In (1), the sentence consists of the subject NP mugeni 'visitor', the verb $r i$ 'be' and the adverbial phrase nomba 'house'. The verb $r i$ 'be' is inflected for person and tense by the prefixes $a$ - and $a$-respectively. The first inflectional morpheme $a$ - on the verb $r i$ encodes the number and person features of the subject NP while the second morpheme $a$ - marks the tense features. In (2), the main verb is the copula $n i$ 'be' and both the subject NP Mugure and the subject complement NP mu-alimo 'teacher' are lexically represented at the logical form configuration. ${ }^{4}$ Thus, the equative meaning of the verb is encoded in the logical form through the morpho-syntactic verb form $a$ - $a$-ri 'be' and $n i$ 'be' in (1) and (2) respectively.

$1.2 \mathrm{R}$-expressions in transitive clauses

A transitive clause contains a verb that licenses a [Spec-Agro] position. There are verbs that license only a single [Spec-Agro] position and those that license two or more [Spec-Agro] positions as can be seen in the following examples.

$\begin{array}{lll}\text { Gitonga } & \text { a-a-munt-ir-e } & \text { mu-ana } \\ \text { Gitonga } & \text { 3SG-tns- stab-PERF-fv } & \text { NC1-child } \\ \text { Gitonga stabbed the child } & \end{array}$

In (3), the transitive verb munt- $a$, 'stab', licenses two logical form positions, that is, the [Spec-Agrs] and the [SpecAgro] position. These are occupied by the NP Gitonga and the NP muana 'child' respectively. Sentences $(1-3)$ show that equative verbs and transitive verbs license the presence of two logical form positions for R-expressions in Gichuka.

In addition to the equative and transitive sentences, there are also derived transitive sentences in Gichuka. In these types of sentences, the valence increasing processes such as the presence of benefactive and causative markers on the verb determine the presence of lexical NPs in sentences, resulting in sentence patterns such as (4-6) below.

(4)

$\begin{array}{llll}\text { Mwiti } & \text { a-a-gur-ir-e } & \text { Mugendi } & \text { ka-ramu } \\ \text { Mwiti } & \text { 3SG-tns-buy-ben-fv } & \text { Mugendi } & \text { NC9-pen } \\ \text { Mwiti bought } & & \\ \text { Mugendi a pen } & & \\ \text { Mwiti } & \text { a-a-rug-ith-i-a } & \text { Mugendi } & \text { irio } \\ \text { MwG-tns-cook-caus-mood-fv } & \text { Mugendi } & \text { food }\end{array}$

Mwiti has made Mugendi cook food

$\begin{array}{llll}\text { Mwiti } & \text { a-a-rug-ith-ir-i-a } & \text { Mugendi } & \text { irio } \\ \text { Mwiti } & \text { 3SG-tns-cook-caus-ben-mood-fv } & \text { Mugendi } & \text { food }\end{array}$

\footnotetext{
${ }^{4}$ The copula $n i$ 'be' is the present form while its past form is aari 'was'. The latter bears a different pronunciation with the verb $a$ - $r i$ 'have.' 
In (4), the verb gur-a 'buy' requires the occurrence of the two object positions where the NP Mugendi is the applied object while the NP karamu 'pen'is the direct object. The applied object NP is licensed by the occurrence of the benefactive morpheme -ir in the verb gura 'buy'. In (5), the verb ruga 'cook' bears the causative morpheme -ithwhich licenses the presence of the NP Mugendi at the position immediately preceded by the verb. Note that in (6), the verb morphology includes both the causative morpheme -ith-and the benefactive morpheme -ir-. When the two morphemes occur on the same root, the NP represented by the causative morpheme is understood as being present at the level of the logical form but not represented at the phonetic form level of representation. Nonetheless, the benefactive morpheme -ir licenses the applied NP Mugendi. The argument structure of the verb in (6) requires the presence of a direct object NP irio 'food'. In contrast to (6), consider (7) where the indirect object (benefactive) marking morpheme $m u$ - on the verb co-occurs with the indirect object (benefactive) lexical NP.

$\begin{array}{llll}* \text { Mwiti } & \text { a-a-mu-rug-ithi-ir-i-a } & \text { Gitonga } & \text { irio }^{5} \\ \text { Mwiti } & \text { 3SG-tns-obj-cook-caus-ben-mood-fv } & \text { Gitonga } & \text { food } \\ \text { Intended meaning: Mwiti has made him cook food for Gitonga } & \end{array}$

In (7), the sentence is interpreted as having four lexical NPs due to the presence of the object prefix mu- 'him' in the verb. Whereas only the benefactive lexical NP is overtly represented in (6) and its corresponding object morpheme is blocked in the verb morphology, the benefactive lexical NP Gitonga co-occurs with its corresponding indirect object (benefactive) morpheme $m u$ - in (7), rendering the sentence ungrammatical. The rule is that the presence of the object marking morpheme mu- 'him' on the verb ruga 'cook' in (7) blocks the presence of the R-expression (lexical NP) denoting the indirect object (benefactive). In this case, the prefix $m u$ - 'him' cannot be coreferential with the NP Gitonga in Gichuka grammar and co-occurrence of the two units within the same syntactic domain is not allowed.

$1.3 \mathrm{R}$-expressions in topic and focus positions

Section 1.1 and 1.2 above demonstrate that the occurrence of $\mathrm{R}$-expressions in sentences is determined by the morpho-syntactic features of the verbs of the sentences in question. In this section, the distribution of R-expressions in topic and focus positions is investigated. A topic position is a position occupied by an R-expression and one that sets the scene for the rest of the sentences in a discourse structure, as can be illustrated with $(8-10)$.

(8)

Ru-gono $\quad r u$ - $u$ NC6-that be
NC6-story
$n$-thegere
NC4-badger
That story is about a lion and a badger

\begin{tabular}{|c|c|c|c|}
\hline $\begin{array}{l}\text { Mu-ruthi } \\
\text { NC2-lion }\end{array}$ & $\begin{array}{l}u \text {-a-ri } \\
\text { 3SG-tns-have }\end{array}$ & $\begin{array}{l}\text { na } \\
\text { with }\end{array}$ & $\begin{array}{l}\text { tu-ana } \\
\text { NC1-children }\end{array}$ \\
\hline
\end{tabular}

The lion had two children

$\begin{array}{llll}N \text {-thegere } & \text { i-t-a-ri } & \text { na } & \text { tu-ana } \\ \text { NC4-badger } & \text { 3SG-neg-tns-have } & \text { with } & \text { NC1-children }\end{array}$

The badger did not have children

In (8), the NP muruthi 'lion' and the NP nthegere 'badger' are [-definite]. This is their first mention in the discourse and, therefore, their indefiniteness arises from low discourse accessibility. ${ }^{6}$ However, in (9) and (10), the two NPs are understood as bearing the feature matrix [+ definite or + topic]. The NPs muruthi 'lion' and nthegere 'badger' occupy the topic positions in (9) and (10). The interpretation of the NPs as [+definite or + topic] in (9) and (10) is attributed to the fact that since they have been mentioned in the preceding discourse, that is, in (8), they are salient in the context and therefore assigned [+ definite, + topic] by virtue of the information structure of the sentence. ${ }^{7}$

\footnotetext{
${ }^{5}$ An asterisk indicates that the sentence is ungrammatical.

${ }^{6}$ Discourse accessibility refers to the cognitive status of the entity referred to by an NP within the discourse structure. For instance, if the entity referred to by the NP has not received any previous mention in the discourse, its accessibility is low. If it has, then the accessibility is high.

7 According to Steube et al (2004:15), an entity, represented by an NP, is salient in the context if it forms part of what is termed the background constituents, that is, it has received a recent mention in the preceding discourse, it can be inferred from the communicative situation or constitutes the background knowledge of the interlocutors in a communication exchange.
} 
A focus position, on the other hand, is a position which is the locus of the new information in sentences. In discourse initial positions such as in (8), lexical NPs such as muruthi 'lion' and nthegere 'badger' bear the feature specification [+ focus]; therefore, they are marked [—definite, - topic]. Once their reference is specified from the context, their feature specification shifts to [- focus]; hence, they receive a [+ definite] description. In this case, the NPs muruthi 'lion' and nthegere 'badger' in (9-10) are understood as identifying identical referents with the NPs muruthi 'lion' and nthegere 'badger' respectively in (8) - entities that are already salient within the discourse.

Besides the overt representation of $\mathrm{R}$-expressions in unmarked focus sentence position such as (8) above, $\mathrm{R}$-expressions also occupy marked focus positions in Gichuka sentences as shown in (11-13).

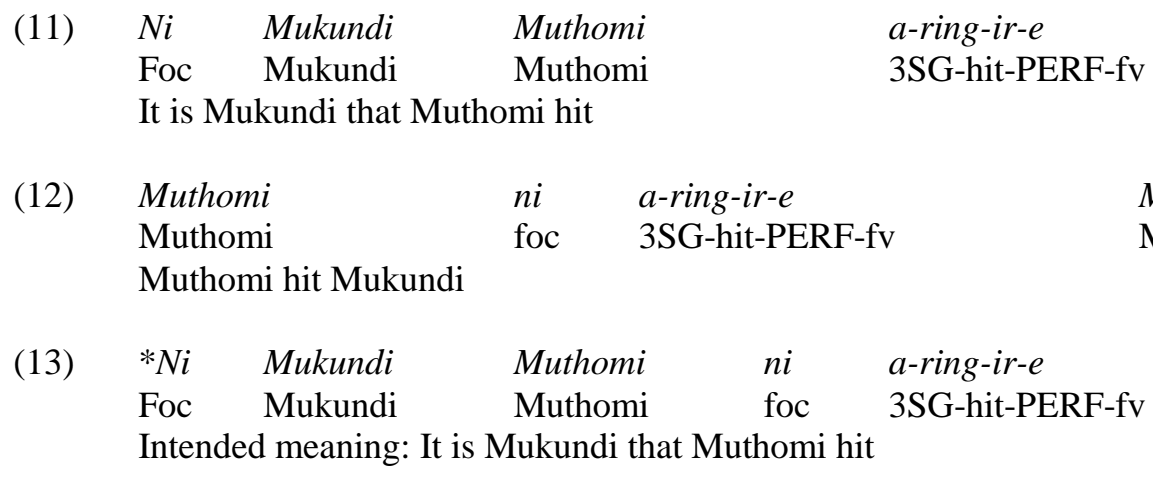

In (11), the NP that is the focus of the sentence, that is, Mukundi occupies the position that immediately follows the focus particle $n i$. The sentence initial position in (11) is occupied by the focus particle $n i$ both at the phonetic form level of representation as well as at the logical form position. The focus phrase (FP), ni Mukundi 'it is Mukundi', immediately precedes the NP Muthomi which precedes the main verb ringa 'hit', resulting in the structure of (11). ${ }^{8}$ In (11), the argument focus is represented because it is the NP Mukundi that bears the new information in the sentence. In (12) the focus particle $n i$ precedes the verbal head, that is, the verb ring- $a$ 'hit'. The position in which the focus particle appears in (11) and the one in which it appears in (12) are mutually exclusive. Consequently, (13) is ruled out as ungrammatical because there are two constituents, the NP Mukundi and the verb ringa 'hit' bearing the feature [+focus] at the logical form. Because of this, the sentence is ruled out by virtue of the violation of the conditions on the economy of derivation (Chomsky, 1995).

2.The syntax - pragmatics interface: assignment of truth conditional meaning to $\mathrm{R}$ - expressions

This section investigates the truth conditional meaning that is assigned to $\mathrm{R}$-expressions in Gichuka phrases and sentences by virtue of the logical form rules. ${ }^{9}$ The assignment of the truth conditional meaning to these expressions present difficulties for the logical form rules because a complete assignment of the truth conditional meaning requires not only the analysis of syntactic features but also contextual features of phrases and sentences. This is illustrated in the sections below.

\subsection{R-expressions in transitive sentences}

As shown in section 1 above, transitive predicates typically bear at least two arguments. In a transitive clause configuration, the verb picks the first $\mathrm{R}$-expression and assigns it the thematic role of agent while the second argument is assigned the semantic role of the patient. There are also transitive predicates in Gichuka that subcategorize for three theta-positions, thus allowing them to occur with three R-expressions. In such clauses, two of the lexical NPs appear as object NPs, as shown in (14) and (15) below.

$\begin{array}{lc}\text { Mwiti } & \text { a-a-gur-ir-e } \\ \text { Mwiti } & \text { 3SG-tns-buy-ben-fv } \\ \text { (14a) } & \text { Mwiti bought a pen for Mugendi } \\ \text { (14b) } & \text { Mwiti bought a pen from Mugendi }\end{array}$

$\begin{array}{llll}\text { Mwiti } & \text { a-a-ret-er-e } & \text { Mugendi } & \text { ka-ramu } \\ \text { Mwiti } & \text { 3SG-tns-sell-ben-mood-fv } & \text { Mugendi } & \text { NC9-pen }\end{array}$

(15a) Mwiti brought Mugendi a pen

\footnotetext{
${ }^{8}$ For a similar discussion on Kikuyu, a language that is closely related to Gichuka, see Horvath, (1995: 40—44).

${ }^{9}$ Truth conditional meaning refers to those aspects of sentence meaning that are determined by the semantic values of each of the lexical items of the sentence and their mode of combination (Larson and Segal, 1995). 
(15b) Mwiti brought a pen on behalf of Mugendi

The presence of the benefactive morpheme -ir, on the verbs gur-a 'buy' and and -er on the verb ret-a 'bring' in (14), licenses the presence of the indirect object Mugendi. ${ }^{10}$ This results in the sentence having both direct and indirect object NPs. The verbs involved license two object NPs where one is assigned the theta role of benefactive while the other one is assigned the role of patient. On interpretation (14a) the verb assigns the NP Mugendi the thematic role of benefactive. On interpretation (14b) the same NP is assigned the thematic role of the source. The meaning of (14) is therefore not truth evaluable in the sense that there is nothing in the logical form configuration to guide the hearer on the choice of interpretation between (14a) and (14b).

Similarly, whether the intended meaning of (15) is (15a) or (15b) cannot be determined by the logical form. In this case, the assignment of the semantic roles assigned to R-expressions Mugendi and karamu 'pen' in double object sentences containing verbs such as gura 'buy' and reta 'bring' is resolved via reference to the context in which the sentence is produced rather than by reference to the logical form rules of the sentence. In the absence of an appropriate context, the sentence fails to yield a determinate meaning as intended by the speaker.

In determining the truth conditional meaning of (14) and (15), the hearer will need to assess the range of possible referents for each of the NPs Mwiti, Mugendi and karamu 'pen' in these sentences, that is, a set of conceptual addresses associated with each of these NPs. This implies that to derive a propositional meaning (one that expresses a definite state of affairs), one has to check which individual (entity) in the actual or possible world of discourse is the denotation of each of the lexically represented NP in (14) and (15).

Therefore, the logical forms of (14) and (15) bear the propositions (explicatures) expressed in (16a-b) and (17a-b) respectively, depending on the context in which the two sentences are produced.

(16a) MWITI BOUGHT A PEN FOR MUGENDI

(16b) MWITI BOUGHT A PEN FROM MUGENDI

(17a) MWITI BROUGHT MUGENDI A PEN

(17b) MWITI BROUGHT A PEN ON BEHALF OF MUGENDI

Whether the propositional meaning of (14) is either (16a) or (16b) and whether the proposition meaning of (15) is (17a) or $(17 b)$ is determined by reference to the context. What the above data suggest is that explicatures are needed to specify the meaning of sentence in terms of the state of affairs either in the actual or possible world. Explicatures such as (16a), (16b), (17a) and (17b) are either true or false depending on the contexts within which the sentences that express them are produced. For instance, ambiguous sentences such as (14) and (15) above will be true if the entity encoded by the NP Mwiti in the world of discourse is consistent with each of the properties encoded by the predicates in (14) or (15) which depends on the context in which the sentence is produced. This suggests that when a sentence is true or false, "it is only because the proposition it expresses is true or false" (Lycan, 2000:81). Propositions are therefore intrinsic truth conditions of utterances of sentences and hence make sentences bear a determinate truth condition.

\subsection{R-expressions in possessive clauses}

In possessive expressions, the NP taking the role of the possessor is more prominent in the context of the discourse situation (Langacker, 1995:58). ${ }^{11}$ In Gichuka, overt morphological realizations, syntactic configurations and contextual parameters play a significant role in determining the truth conditional meaning of possessive expressions as can be seen in sections $2.2 .1-2.2 .5$ below.

\subsubsection{R-expressions in simple possessive clauses}

To mark possessive relations in simple possessive clauses, Gichuka exploits morphological processes such as bound morphemes affixed to nouns, as shown in (18) below.

\begin{tabular}{|c|c|c|}
\hline (18) & Munene & $a-k u-o n-a$ \\
\hline
\end{tabular}

Munene has found a wife/his wife

\footnotetext{
${ }^{10}$ The benefactive morpheme can be pronounced as either [-ir] or [-er] depending on the phonological environment within which it occurs. Nonetheless, the present study will not delve into the morphophonemics of the language.

11 According to Langacker (1995), the possessor is the reference point in a possessive construction. Therefore, it is more semantically dominant at the level of the interpretation of a possessive construction.
} 
In (18), the NP $m u-k a$ 'wife' expresses a variety of meanings depending on the context within which the sentence is produced. For instance, if the NP Munene is understood to be a bachelor who has been trying to find someone to marry, an indefinite reference, 'a wife' is the most likely interpretation. However, if the NP is produced in reference to a man whose wife had been missing, a definite description, i.e., 'his wife' is the most likely interpretation.

Therefore, the reference for the NP $m u-k a$ is determined by the hearer's knowledge of the social status of the referent encoded by the NP Munene in (18). It is this knowledge that enables the hearer to arrive at the right propositional form that represents the truth conditional meaning. This suggests that the possessor/possessee relation in (18) is a pragmatic matter, not a purely syntactic one. Now, consider (19) below for a similar analysis involving a contracted possessive NP.

$$
\begin{array}{lll}
M u \text {-ka-gu } & n i & \text { mu-ruaru } \\
\text { NC1-wife-your } & \text { be } & \text { NC1-sick }
\end{array}
$$

Your wife is sick

In (19), the possessive relation is morphologically marked through the suffix - gu 'your' on the noun muka 'wife'. The possessed NP bears the affix that marks possession. ${ }^{12}$ The reference of the bound (possessive) morpheme $-g u$ 'your' is determined by the context within which the NP muka-gu 'your wife' is produced. The hearer assigns the semantic value of the possessive pronoun and combines this value with the contextual information to derive the propositional meaning through a process termed saturation. ${ }^{13}$ Once all the linguistic elements in a sentence are assigned semantic values, the sentence becomes a full proposition that expresses a definite state of affairs. So, whether (19) is true or false is determined once the referent of the suffix $-g u$ 'your' is identified from the context via saturation. This is done by assigning the addressee of (19) from the discourse context; otherwise, the sentence is neither truth or false. Now consider (20) below for an analysis of a sentence containing a lexically represented possessive pronoun.

$\begin{array}{lllll}\text { Mu-alimo } & w a-k u & n i & m u-k u r u & \text { muno } \\ \text { NC1-teacher } & \text { NC1-your } & \text { be } & \text { NC1-old } & \text { too/very }\end{array}$

Your teacher is very/too old

In (20) the possessive relation is marked by a lexically represented possessive pronoun waku 'your'which functions as the modifier of the NP mu-alimo 'teacher'. The latter is assigned the role of the possessee. The possessive pronoun waku 'your' is overtly inflected with a morpheme wa- to mark the phi-features of the head of the possessive NP (to reflect the number and the grammatical class of the head of the possessive phrase). In this case, the modifier waku 'your' stands in agreement relation with the head of the NP, that is, the NP mualimo 'teacher'. In addition, the NP mualimo 'teacher' also stands in agreement relation with the post verbal adjective mukuru muno 'very/too old'in the sentence final position. This agreement is marked by the prefix mu- on the noun mu-alimo 'teacher' and the adjective mu-kuru 'old'. In determining the propositional meaning of (20), the hearer has to activate the right concept for the NP mualimo 'teacher' since there are more than one candidate referents for this NP and the speaker must have intended the NP to encode a specific entity from the context.

In Gichuka, the possessive meaning is also marked through syntactic realization as can be seen in (21) below.

$\begin{array}{lllll}\text { Ma- } a-r-i & n a & m \text {-buri } & \text { m-ingi } & \text { muno } \\ \text { 3PL-tns-have-fv } & \text { with } & \text { NC4-goats } & \text { NC4-many } & \text { very } \\ \text { They had very many goats } & & & \end{array}$

In (21), the verb - $r i$ 'have' imposes a possessive relation between the entity encoded by the third person prefix $m a$ 'they' and the NP mburi 'goats'. The prefix ma- 'they' encodes the possessor while the lexical NP mburi 'goats' encodes the possessee. The agreement relation is limited in this type of construction in the sense that the verb -ri 'have' agrees only with a contextually salient NP marked by the prefix $m a$-. This prefix marks the phi-features of an entity that is outside the logical form of (21). However, there is no agreement relationship between the phi-features of the prefix $m$ - on the equitive verb $r i$ and the possessee NP $m$-buri 'goats'. In producing (21), the speaker has an entity anchored in the mind and therefore copies the features of the entity on the verb so that the morphological features of the verb are

\footnotetext{
${ }^{12}$ In Gichuka, this morphological marking of genitive-possessive relations is limited to a restricted set of lexical items that only mark kinship relations such as wife, husband, father, etc. Notice that the suffix does not change regardless of the phifeatures of the possessor NPs. In these types of lexical items, the possessor NP contains three units, that is, muka-wa-ku 'wife-of-yours' but morphophonemic processes determine that the reduced form mu-ka-gu is pronounced.

${ }^{13}$ See (Recanati, 1993, 2004, Sperber and Wilson, 1986 and Carston 2002) for a detailed discussion of the concept of saturation. Within the relevance theoretic framework, the combination of the linguistic information and contextual information in the derivation of the propositional meaning of sentences is referred to as saturation.
} 
determined by an entity that is anchored in the discourse context rather than an NP that is located within the logical form position of the sentence. The entity encoded by the morpheme ma- may bear either the feature [+ focus] or [focus]. The topic-marking morpheme $m a$ - 'they' on the verb - $r i$ 'have' overtly reflects the phi-features of the intended referent from the discourse context.

If the NP that is assigned the possessor role is [+ plural] but the possessee is [-plural], the equitive verb $-r i$ 'have' bears a plural marking. If, on the other hand, the possessor is [+ singular], the verb bears a singular marking at the phonological form level. In other words, it is the phi-features of the entity that is anchored in the context that determines the morphological features of the verb.

\subsubsection{R-expressions in $n i$ predicative possessive clauses}

In a typical $n i$ predicative possessive clause, the possessive pronoun occupies the postverbal position while the $\mathrm{R}$-expression, that is, the possessed NP, occupies the sentence initial position as can be seen in (22).

$$
\begin{array}{lllll}
\text { Mbuku } & \text { i-no } & n i & y \text { - } a & \text { Muthomi } \\
\text { NC4-book } & \text { NC4-this } & \text { be } & \text { NC4- ASSOC } & \text { Muthomi }
\end{array}
$$

(22a) This book is Muthomi's

(22b) This is Muthomi's book

The NP Muthomi in (22) stands in a predicative position with respect to the NP mbuku ino 'this book'. In (22), it is the NP Muthomi that is assigned the role of the possessor. On interpretation (22a) the NP mbuku 'book' receives an indefinite description at the logical form level of representation while on interpretation (18b), it receives a definite description. The choice of which interpretation is derived from (22) is not constrained by any morpho-syntactic unit within the logical form configuration of the sentence. The specification of the particular semantic interpretation that is intended by the speaker is resolved via reference to the context of the sentence. In deciding whether the meaning of (22) is (22a) or (22b), one must complete the logical form of (22) by referring to the context in which the sentence is produced. For instance, if there was no mention of the NP book in the preceding discourse, then (18a) would be the most likely interpretation. However, if there was a mention of it and the NP was the most contextually accessible, this would result in the interpretations in (22b).

In addition, the intended referent for the NP Muthomi must be specified for the sentence to yield a truth propositional meaning. For instance, consider this scenario for (22). Munene is a lecturer and is sitting in his office at the faculty of arts with one of his students, Gatuiri. Then one of his fellow lecturers, Muthomi, enters his office and finds Munene and his student having a conversation. The two colleagues exchange a few words and then Muthomi walks out. Then, Gatuiri, lifts a certain text book she has been holding and utters (22). Now, assume that there exist in the world of discourse multiple candidate referents for the NP Muthomi, that is, $M U T H O M I_{1}, M U T H O M I_{2}, M U T H O M I_{3}$, and so on, say for instance where MUTHOMI 1 is Munene's colleague in the faculty, $\mathrm{MUTHOMI}_{2}$ is Munene's late grandfather and MUTHOMI ${ }_{3}$ is Munene's uncle. According to the relevance theory, considerations of speaker's abilities (his or her knowledge of the world) and preferences play a critical role in the derivation of the truth conditional meaning of sentence. For instance, the hearer of (22) recognizes that the student does not know much about Munene's family relations and therefore, there is no way the speaker would have intended the concepts $\mathrm{MUTHOMI}_{2}$ and $\mathrm{MUTHOMI}_{3}$. In that case, the concept MUTHOMI 1 will be the most accessible interpretation of the NP Muthomi in (22).

\subsection{3 $\mathrm{R}$-expressions in - ri possessive clauses}

Just like in deriving the meaning of $\mathrm{R}$-expressions in $n i$ predicative possessive clauses, the meaning of the $\mathrm{R}$-expressions in - ri possessive clauses display semantic under-determinacy. This is partly due to the semantic ambiguity of the verb -ri and to the obligatory contextual factors that determine the truth conditional properties of sentences within which genitive expressions occur. In Gichuka, the postposed possessive expressions bear the

\begin{tabular}{|c|c|c|}
\hline (23) & Mu-alimo & $a-a-r-i$ \\
\hline
\end{tabular}
possessed NP immediately preceded by the copula verb - $r i$ 'have' as shown in (23).

(23a) The teacher has a house

(23b) The teacher is in the house

Sentence (23) is ambiguous between (23a) and (23b). On interpretation (23a) the relationship between the two $\mathrm{R}$-expressions, that is, the NP mualimo 'teacher' and the NP nomba 'house', is that of possession. The NP mualimo 'teacher' is assigned the possessor role and the NP nomba 'house' in the clause final position is assigned the role of the possessee. On interpretation (23b), the NP nomba 'house' is assigned a locative role at the level of logical form representation. In (23), the NP nomba 'house' can be assigned both the possessee role and the location role. There is no morpho-syntactic unit in the logical form to guide the hearer on the choice of the interpretation of (23). 
A similar problem of semantic under-determinacy arises in the recovery of truth conditional meaning assigned to $\mathrm{R}$-expressions in (24) below.

$$
\begin{array}{lll}
\text { (24) } & \begin{array}{l}
\text { Mu-alimo } \\
\text { Teacher 3 } \quad a-a-r-i \quad \text { SG-tns-have-fv }
\end{array} & \text { ndaa } \\
\text { (24a) } & \text { The teacher has a louse on him } \\
\text { (24b) } & * \text { The teacher owns a louse } &
\end{array}
$$

In (24), there is no relation of possession between the entity marked by the NP mualimo 'teacher' and the NP ndaa 'louse'. The logical form yields a meaning that the NP ndaa 'louse' is on the entity encoded by the NP mualimo 'teacher' and therefore the latter NP is assigned the thematic role of the location rather than that of the possessor. The interpretation in (24b) is unavailable in most contexts given the interlocutors' encyclopaedic knowledge of lice and people according to which the latter never own the former. The saturation of the logical forms in (23a), (23b) and (24a) results in propositional forms (explicatures) in (24c), (24d) and (24e) respectively.

\section{(24c) THE TEACHER HAS A HOUSE \\ (24d) THE TEACHER IS IN THE HOUSE \\ (24e) THE TEACHER HAS A LOUSE ON HIM}

Notice that unlike in (23) where the sentence yields two propositional forms (24c) and (24d), the saturation of (24) yields only (24a) as the propositional form. The encyclopaedic knowledge determines that only one proposition is possible for (24). This implies that the NP ndaa 'louse' is located at the entity encoded by the NP mualimo 'teacher'. On this account, the knowledge of the interlocutors limits the state of affairs in which the NP mu-alimo at the sentence initial position and the NP ndaa 'louse' can exist. Clearly, a possessive relation in this case is unlikely in most contexts. The substitution of the NP ndaa 'louse' with another NP such as nomba 'house' as exemplified with (23) opens a possibility of genuine possessive relation. To determine the truth conditional meaning of sentences such as (23) and (24), the hearer has to determine the context within which the sentence is produced. In this case, the locative and possessive distinctions for (24) are clear once the context of the sentence is determined.

Now, consider the conversation in (25) below for a demonstration of how explicatures are derived during the interpretation of sentences.

$$
\begin{aligned}
& \text { A: M-bia i-ka-uma ku? } \\
& \text { NC4-money NC4-tns-come where? } \\
& \text { Where will the money come from? }
\end{aligned}
$$

$\begin{array}{llll}\text { B: } & \text { Muthomi } \quad a-r-i & \text { na } & \text { m-bia } \\ \text { Muthomi } & \text { 3SG-have-fv } & \text { with } & \text { NC4-money } \\ \text { Muthomi has the money } & & \end{array}$

B's response encodes the possessive relationship that describes a state of affairs in a world where part of the possessions that the NP Muthomi has is a subset of money, hence the relationship of possession emerges from the sentence. Here, the NP Muthomi is assigned the role of possessor while the NP mbia 'money' is assigned the role of possessee. The second aspect of the truth conditional status of B's response describes a state of affairs where money is available. In this case, the NP Muthomi is assigned the role of the source. In the recovery of the truth conditional meaning from the logical form of B's response, the hearer of B has to resolve the ambiguity between the meaning that Muthomi has the money and the meaning that money is available. Decoding B's logical form derives the propositional forms in (25B1) and (25B2) below.

\section{(25B1) MUTHOMI HAS THE MONEY}

(25B2) Intended meaning (propositional form): MONEY IS AVAILABLE

While (25B1) is an explicature, (25B2) is an implicature. Clearly, the speaker of (25) is communicating (25B2), and not (25B1), as an indirect or implied answer to A's question. Note that decoding of (25B1) does not result in the propositional form expressed in (21B2). According to Relevance Theory, both explicatures and implicatures such as (25B1) and (25B2) respectively are derived by a process of mutual adjustment. The hearer follows a path of least (processing) effort by considering hypotheses about explicit content and implicatures in their order of accessibility until he or she arrives at the proposition that satisfies his expectations of relevance. For instance, in processing (25) the hearer has a highly accessible assumption (proposition), that is, MONEY IS AVAILABLE as a potential implicature of the utterance even before a complete explicature in (25B1) is derived. 
Thus, the logical form of B's response is semantically underspecified and therefore the sentence must be enriched through contextual information to determine the meaningintended by the speaker. Explicatures such as (25B1) and implicatures such as (25B2) are either true or false depending on the contexts within which sentences that express them are produced. While explicatures are derived through a pragmatic process of saturation, implicatures are derived through a pragmatic process of (free) enrichment. ${ }^{14}$ The derivation of the explicatures involves the development of of logical forms which, in most cases, are semantically underspecified.

\subsection{4 $\mathrm{R}$-expressions in $\mathrm{NP}-\mathrm{a}-\mathrm{NP}$ possessive NPs}

The $N P-a-N P$ possessive NPs are possessive NPs that bear two NPs and an intervening preposition $-a$ between them. The leftmost NP within the possessive NP is assigned the semantic role of the possessee while the NP preceded by the preposition $-a$ is assigned the role of the possessor, as can be seen in (26).

$$
\begin{array}{lllll}
G i \text { - } k i & n i & g i-t i & k i-a & b a b a \\
\text { NC2-this } & \text { be } & \text { NC3-seat } & \text { NC3-ASSOC } & \text { father }
\end{array}
$$

This is my father's seat

In (26), the preposition $k i-a$ 'of'selects the NP baba 'father' as its complement and introduces it into the derivation, resulting in the logical form configuration in (27).

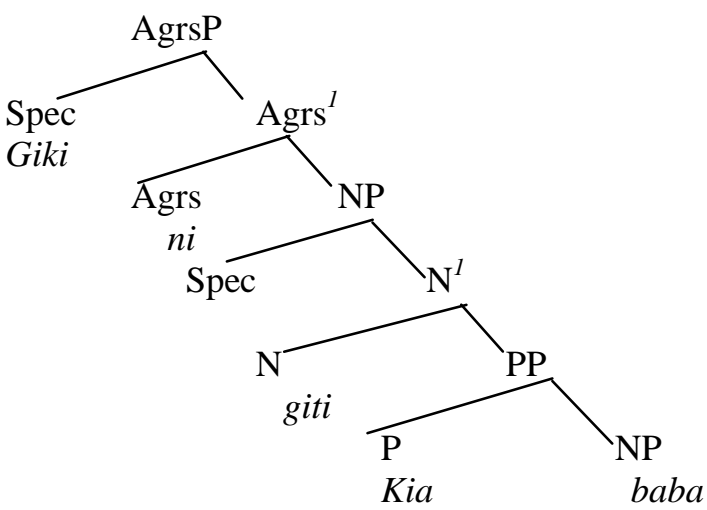

In (27), the NP baba 'father'is licensed in the lower sentence position and bears the semantic role of the possessor as assigned by the preposition kia 'of'. The NP giti 'chair' raises to the [Spec-Agrs] position of the sentence to check its case features. Once the NP baba 'father' merges with the preposition, it is assigned the theta role of the possessor via merge. ${ }^{15}$ Since the semantic properties of the head of VP, that is, the copula $n i$ 'be' in (26) block it from assigning theta roles at logical form, the NP gi-ti ki-a baba 'my father's chair', functions as the complement of the determiner giki'this' at the clause initial position. The entire possessive phrase gi-ti ki-a baba 'my father's seat'functions as the subject complement.

As can be seen in (26) and (27) it seems there is no strict adjacency between the NP giti 'chair' and the preposition $-a$ 'of'. In Gichuka, modifiers of the possessed NP giti 'chair' in (26) and (27) can intervene between the preposition $-a$ 'of' and the possessed NP giti 'chair' as illustrated by the grammaticality of (28).

$$
\begin{aligned}
& G i-k i \quad n i \quad g i-t i \\
& \text { NC2-this } \quad \text { be } \quad \text { NC3-seat } \\
& b a b a \\
& \text { father } \\
& \text { This is my father's big seat }
\end{aligned}
$$$$
g i-i
$$$$
\text { NC2-det }
$$$$
\text { ki-nene }
$$$$
\text { NC2-big }
$$$$
\text { ki-a }
$$

However, strict adjacency between the preposition $-a$ 'of' and the possessor NP $b a b a$ 'father' is required. As the reader can see, the introduction of additional constituents between the preposition and the possessor NP results in the ungrammaticality of (29).

\footnotetext{
${ }^{14} \mathrm{By}$ (free) enrichment is meant that the process of deriving the speaker's intended meaning is linguistically unconstrained, that is, free, top-down, optional pragmatic processes. For a thorough discussion of the distinction between saturation and (free) enrichment, see Recanati $(1993,2004)$.

${ }^{15}$ Radford $(1997,2004)$ following Chomsky (1995) argues that theta roles are assigned via the operation merge.
} 


$\begin{array}{llllll}* G i-k i & n i & g i-t i \quad k i-a & g i-i & k i-n e n e & b a b a \\ \text { NC2-this } & \text { be } & \text { NC3-seat } & \text { NC3-ASSOC NC2-det } & \text { NC2-big } & \text { father }\end{array}$

Intended meaning: This is my father's big seat

The ungrammaticality of (29) results from the fact that the constituents gi-i 'the' and kinene 'big' intervene between the preposition kia 'of' and the possessor NP baba 'father'. The presence of gi-i ki-nene 'the big one' between the preposition kia 'of' and the possessed NP giti 'chair' blocks the latter from merging with the former to yield a single syntactic unit at the level of the logical form, resulting in the ungrammaticality of the sentence.

In $N P-a-N P$ possessive clauses, the possessive phrase expresses semantic under-determinacy, as can be seen in (30) below.

$$
\begin{array}{llll}
\text { A-gur-ir-e } & \text { m-bicha } & y-a & \text { Mugure } \\
\text { 3SG-buy-PERF-fv } & \text { NC4-picture } & \text { NC4- ASSOC } & \text { Mugure }
\end{array}
$$

3SG-buy-PERF-fv NC4-pict
He/she bought Mugure's picture

(30a) NP - The picture of Mugure

(30b) NP - The picture by Mugure

In (30), the NP Mugure is the complement of the preposition ya 'of'. The latter is the specifier of the PP ya Mugure 'of Mugure'. Sentence (30) has two possible logical forms representations as illustrated by (30a) and (30b) above, which in turn yield propositional forms (30A1) and (30B1) respectively.

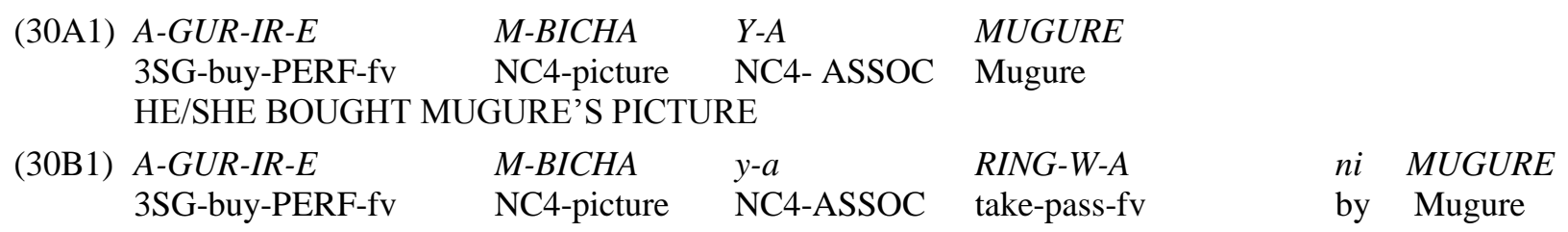

On interpretation (30A1) the NP Mugure has the possessive relationship with the NP mbicha 'picture'. On this interpretation, the picture belongs to Mugure. On interpretation (30B1), Mugure is the agent of the NP mbicha 'picture', that is, Mugure must have taken the picture herself. (30B1) therefore represents a state of affairs in which the picture was taken by Mugure. In (30A1) the relationship between the NP mbicha 'picture' and the NP Mugure is that of possessee and possessor while in (30B1), the relationship is that of possessor and agent. ${ }^{16}$ The logical form of (30) fails to provide an accurate prediction of the choice of interpretation for the sentence. It is only at the propositional form level where the sentence can either be true or false as the derivation of the explicatures (30A1) and (30B1) will also involve the assignment of semantic values of the pronominal morphemes on the verb morphology.

\subsubsection{R-expressions in double-possessive NPs}

This section focuses on the structure and meaning of R-expressions in double-possessive NPs. The recovery of the meaning of the double possessive NPs via reference to their syntactic representation leads to multiple semantic representations, as illustrated by (27).
M-bicha $\quad y$ - $a$
NC4-picture NC4-ASSOC Muthomi
$\begin{array}{ll}y-a & \text { Mugure } \\ \text { NC4-ASSOC } & \text { Mugure }\end{array}$
(31a)
(31b)
(31c) Muthomi's view of Mugure
The picture of Mugure that Muthomi owns
(31d) The picture of Muthomi that Mugure owns

Sentence (31) is ambiguous with regard to the role that the NP Muthomi plays vis-à-vis the NP mbicha 'picture'. In (31a) the NP Muthomi is the possessor and is also the agent in the possessive relation encoded by the logical form. In (31b) the NP Muthomi stands in an agent/theme relation with respect to the NP mbicha 'picture'. In (31c) the NP Muthomi stands in the theme/experiencer position in relation to the NP mbicha 'picture' and in (31d), the NP Mugure is assigned the thematic role of the possessor. The additional syntactic constituent, i.e., the PP $y$-a Muthomi, 'of Muthomi', fails to offer any restriction on the scope of the interpretive ambiguity. The actual meaning of the double possessive NPs is therefore determined by factors that are beyond the logical form constraints.

\footnotetext{
${ }^{16}$ The picture-type of possessive-genitive relations have been discussed extensively (see for instance, Chomsky, 1981, 1995, Chafe, 1970 and Lyons, 1968 and Haegeman, 1994).
}

152 
What the above situation brings out is that there are different interpretations for the constituents that are dominated by the NP projection at the logical form of the possessive NPs.

The context in which (31) is produced is the determining factor in the assignment of the theta role of the NPs within the possessive phrases. In (31), the ambiguity arises from the number of theta roles that can be assigned to the NPs Muthomi and Mugure once they are merged with the preposition $y a$ 'of' during the operation merge. In derivations such as (31), there is clearly a multiplicity of theta roles that $\mathrm{R}$-expressions receive within possessive phrases. Whether the NPs Muthomi and Mugure are assigned thematic roles such as agent, possessor, possessee and experiencer at the logical form level of representation is a matter that is not determined solely by the logical form configuration of the sentence.

\section{$2.3 \mathrm{R}$-expressions in active and passive sentences}

It is assumed within the generative grammar (Chomsky 1977, 1981,1995, Haegeman 1994) that a passive sentence bears the same truth conditional meaning as its active counterpart, as shown in (32) and (33) below.

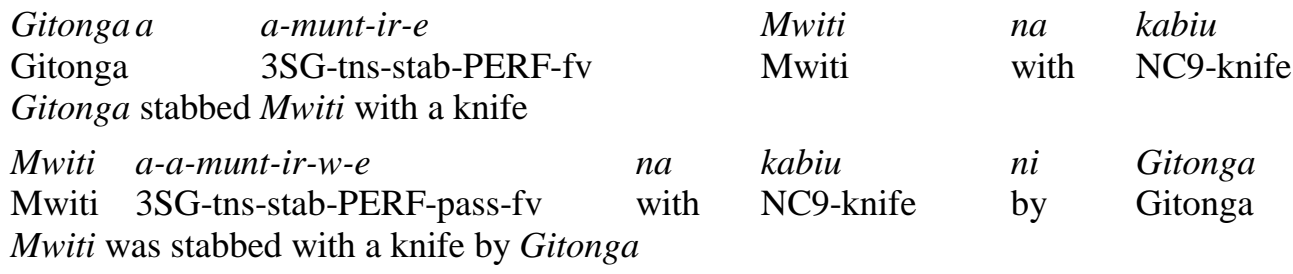

The identity of the truth conditional meaning between the passive and its active counterpart arises from the assumption that at the logical form configuration, the NPs in passive and active sentences bear identical theta roles. Passivization is therefore viewed as a meaning preserving operation (Chomsky, 1995:115). For instance, in (32) the NP Mwiti is the complement of the verb munta 'stab'; it is assigned the theta role of the patient at logical form. Similarly, the NP Mwiti in (33) is the complement of the verb munta 'stab' but has moved to the [Spec-Agro] position to check its case features. In addition, it is assigned the semantic role of the patient after it has merged with the verb.

Nonetheless, there are active sentences in Gichuka that appear to differ in meaning from their passive counterparts, as shown in (34) and (35).

\begin{tabular}{|c|c|c|c|}
\hline $\begin{array}{l}\text { A-rithi } \\
\text { NC1-shepherds }\end{array}$ & $\begin{array}{l}m a-i-r u g-a g-a \\
\text { 1PL-obj-cook-IMP-fv }\end{array}$ & $\begin{array}{l}w a \\
\text { every }\end{array}$ & $\begin{array}{l}\text { mu-thenya } \\
\text { NC2-day }\end{array}$ \\
\hline \multicolumn{4}{|c|}{ The shepherds cook them every day } \\
\hline $\begin{array}{l}\text { I-rug-ag-w- } a \\
\text { 3SG-cook-IMP-pass-fv }\end{array}$ & $\begin{array}{l}\text { wa } \\
\text { every }\end{array}$ & $\begin{array}{l}\text { mu-thenya } \\
\text { NC2-day }\end{array}$ & $\begin{array}{l}\text { (ni } a \text {-rithi) } \\
\text { (by NC1-shepherds) }\end{array}$ \\
\hline
\end{tabular}

Let us hold the standard assumption that the presence of the PP ni arithi 'by shepherds' in the clause final position in (35) can be omitted without changing the semantic representation of the sentence. What determines the semantic representation of the sentence is the assignment of the referent to the bound pronominal morpheme $i$ - on the verb ruga 'cook' in (35). The morpheme $i$ - can be assigned any semantic value that is different from the one assigned to the bound pronominal morpheme $m a$ - in (34). Since the morpheme $i$ - cannot independently pick a specific $\mathrm{R}$-expression (lexical NP) in the universe of discourse, the sentence cannot be assigned a specific meaning by virtue of the incorporation of the bound morpheme on the verb ruga 'cook'. For instance, $i$ - limits the choice of the interpretation to NPs that belong to noun class 3 such such as indo 'things', class 4 nouns nama 'meat', yombe 'cows' m-buri 'goats', ndigu 'bananas', etc. There is nothing in the logical form configuration of either (34) or (35) to guide the hearer on the correct interpretation of the reference for the bound pronominal morpheme $i$-. For the hearer of (35) to arrive at a fully propositional meaning, he/she must complete the logical form of the sentence with contextual information to specify the intended referent of the bound pronominal morpheme on the verb ruga 'cook' and arrive at the correct semantic interpretation that is identical with the one in (34).

Just as is the case with (34) and (35), the truth conditional properties of (36) below may not necessarily entail those of (37), unless they are determined by the context of the sentence.

$\begin{array}{lll}\text { Ci-ana } & \text { i-i-rug-ag- } a & \text { irio } \\ \text { NC1-children } & \text { 3PL-tns-cook-IMP-fv } & \text { food } \\ \text { Children cook food } & & \end{array}$




Irio $\quad$ i-rug-ag-w-a
Food $\quad$ 3SG-cook-IMP-pass-fv
Food is cooked (by children)

(ni ci-ana)

(by NC1-children)

Food is cooked (by children)

Sentences (36) and (37) raise a fundamental question with regard to the meaning equivalence in terms of truth conditions and entailments. For instance, (36) does not necessarily entail the truth of (37). In other words, it is not the case that (37) is always true in all contexts where (36) is true. For the hearer of (37) to arrive at the truth conditional meaning that is identical with that of (36) the referent of the NP irio 'food' referred to in the sentence must be fully specified in (37) so that it matches with the specific food that the speaker of (36) intended at the time of producing the sentence. The specificity of both the NP irio 'food' and the NP ciana 'children' is required in (36) and (37). The intended meaning of the NP is attained by narrowing the reference of the concept irio 'food' by use of the discourse context so that it attains an interpretation that matches the one intended by the speaker.

Chomsky (1977:30) argues that in sentences such as (36) and (37), "there is a universal quantifier over the subject lurking somewhere in the interpretation."According to Chomsky, an active sentence such as (36) derives the interpretation that all food is cooked whether or not this is the typical property of any food while the passive form says nothing about all food. On realizing that the truth conditional meaning of such sentences is context-dependent, Chomsky concedes that in sentences with generic indefinite NPs such as irio 'food', there exist extra grammatical factors such as discourse context that determine the truth conditional status for sentences (1977:30, fn 11). As the reader can see, the specification of the meaning of the bound pronominal morpheme $i$ - in (35) and the specification of the intended truth conditional meaning of the NPs such as irio 'food' in (37) require some degree of reference to the context. In this case, the context plays a major role in determining the intended referent of not only the bound pronominal elements but also the lexical NPs for the sentence to express the truth conditional meaning.

\subsection{R-expressions in expletive sentences}

Expletive sentences are also known as existential sentences. The assumption is that in these types of sentences, the referent encoded by the R-expression introduced by the verb $r i$ 'be' exists in the extra-linguistic world. In Gichuka, the expletive meaning is encoded by the morpheme $k u$ 'there'. A typical expletive sentence in Gichuka begins with the expletive particle $k u$ 'there' followed by the morpheme $n a$ 'with' and then by a lexical NP, as shown in (38).
Ku-a-r-i
$n a$
iria
kabati-ni
There-tns-be-fv with
milk
cupboard-loc
There was milk in the cupboard

The expletive $k u$ - 'there' is prefixed on the verb $r i$ 'be' in the sentence initial position. The associate NP for the expletive particle is usually a common noun such as iria 'milk' in (38). It is located at the postverbal position within the prepositional phrase. There are factors that come into play when determining the truth conditional status of (38) even after all the grammatically driven saturation has applied. For instance, it is hard to derive from the logical form what the relationship between the two NPs, that is, the NP iria 'milk' and the NP kabati 'cupboard' is in the sentence. If there were a few sprinkles of milk on cupboard walls and shelves, the speaker would produce (38). Similarly, if there was a vacuum flask, a cup, a carton or a basin of milk in the cupboard, the speaker would still produce the same logical form. ${ }^{17}$

Whereas the English-type languages break down the generic meaning of the mass nouns such as milk, hearers of Gichuka rely on the aspects of the context to specify the intended meaning for some of the sentences containing such nouns. This is a case of semantic indeterminacy at the logical form level because decoding the logical form only does not yield a determinate truth evaluable semantic interpretation for the NP iria 'milk' in the sentence. Hence, the entire sentence cannot be specified as either being true or false by virtue of its logical form. There is nothing in the logical form to specify what semantic interpretation of the NP iria 'milk' the speaker of (38) intended. So, the sentence is not amenable to truth conditional analysis unless saturation has applied.

Further, consider (39) and (40) for a demonstration of how the hearer's knowledge of the context of speech situation can specify the meaning of the $\mathrm{R}$-expressions in expletive sentences.
Ku-a-r-i
na
$m$-buku
cukuru
There-tns-be-fv with
NC4-book
school
(39a)
There was a book in the school

\footnotetext{
${ }^{17}$ See Carston, (2002) for a similar suggestion for English sentences.
} 
(39b) There were books in the school

$\begin{array}{llll}\text { Ku-a-r-i } & \text { na } & \text { n-tumu } & \text { thoko } \\ \text { There-tns-be-fv } & \text { with } & \text { NC9-bean } & \text { market }\end{array}$

(40a) There was a bean in the market

(40b) There were beans in the market

Sentence (39) is ambiguous between (39a) and (39b). Given that the NP $m$-buku 'book' does not inflect for number features, the sentence is ambiguous between (39a) and (39b). Despite this ambiguity, the most likely interpretation is (39b). Given the hearers' background knowledge of schools and their relationship with books, the most likely interpretation of (39) is (39b) as opposed to (39a). Similarly, (40) is ambiguous between (40a) and (40b). Whereas (40a) is still a possible logical form, it is an unlikely interpretation in most contexts given the information that speakers and hearers have about markets.

Within the generative tradition, it is assumed that the expletive morpheme and the associate NP (lexical NP) immediately preceded by the preposition form a chain. According to Chomsky's (1995) Minimalist Program, the expletive morpheme and the associate NPs must stand in certain structural position in relation to each other so that they form a chain in which the associate NP is the head of the chain. At logical form, both the head of the chain and the expletive receive identical interpretation. However, this account fails to account for the interpretation of (38-40) because the chain that is formed by the two logical form elements involves a lexical NP and a bound morpheme ' $k u$-'. Since the latter does not occupy a legitimate logical form position, it is difficult to see how it forms a chain with the associate NPs. Further, there is no requirement for overt agreement between the expletive particle $k u$ - 'there', the verb $r i$ 'be' and what Chomsky (1995) regards as the associate NP, that is, the NPs iria 'milk', mbuku 'books' and ntumu 'beans' in (38), (39) and (40) respectively. ${ }^{18}$ Consequently, the meaning of such constructions cannot be explained by reference to only the morpho-syntactic features of the language.

\section{Conclusion}

The study has shown that the presence of $\mathrm{R}$-expressions in sentences is determined by the morpho-syntactic features of the verbs of the sentences in question. Valence increasing processes such as the presence of benefactive and causative morphemes require the presence of at least three $\mathrm{R}$-expressions in sentences while valence decreasing processes such as subject and object marking reduce the number of arguments occurring with transitive verbs.

Further, it has emerged that the definite and indefinite references of $\mathrm{R}$-expressions are determined by the context of sentences. Whether an $\mathrm{R}$-expression receives a definite or indefinite interpretation is determined by factors that are beyond logical form rules. It has also emerged that the process saturation and (free) enrichment of sentences with $\mathrm{R}$-expressions play an important role in determining the truth conditional meaning of the sentences.

It has been shown that the logical form faces difficulty in accounting for the interpretation of the semantic roles assigned to $\mathrm{R}$-expressions in sentences with double objects and possessive expressions. Specifically, it has emerged that the rules of grammar fail to resolve the semantic ambiguity that is characteristic of sentences with double objects as well as those with possessives NPs. The features of the context such as the hearers' knowledge of the subject of the discourse play an important role in determining the semantic equivalence between active and passive sentences with generic nouns.

Finally, the lack of overt morphological agreement between R-expressions immediately preceded by the copula verb $r i$ 'be' in Gichuka expletive sentences means that the interpretation of the relationship between the expletive particle $k u$ - 'there' and its associate lexically represented NP cannot be adequately accounted for within the Minimalist Program. As has been shown, the interpretation of the meaning of $\mathrm{R}$-expressions in expletive sentences is largely determined by the context.

\section{References}

Burzio, L. (1986) Italian Syntax. Dordrecht: Reidel.

Carston, R. (2002) Thoughts and Utterances. The Pragmatics of Explicit Communication. Oxford: Blackwell.

\footnotetext{
${ }^{18}$ Chomsky (1995), following Burzio (1986), treats an expletive as a logical form affix for its associate NP and argues that when its syntactic features correspond with those of its associate NP, it must fulfill the restrictive locality constructions at Dstructure level of representation. In addition, he argues that the agreement for number features in expletive constructions occurs between the associate NP and the verb rather than between the expletive and the verb.
} 
Chafe, W. (1970) Meaning and Structure of Language. Chicago: University of Chicago Press.

Chomsky, N. (1977) Essays on Form and Interpretation. Amsterdam: Elsevier.

Chomsky, N. (1981) Lectures on Government and Binding. New York: Foris publications.

Chomsky, N. (1995) The Minimalist Program. Cambridge: MIT Press.

Haegeman, L. (1994) An Introduction to Government and Binding Theory. Oxford: Stockwell.

Horvath, J. (1995) Structural focus, structural case, and the notion of feature agreement. In Kiss, E. (1995). Discourse Configurational Languages. Oxford: Oxford University Press, pp. 28-64.

Langacker, R. (1995) Possession and possessive constructions. In Taylor, R. and McLaury (eds.) Language and Cognitive Construal of the World. Oxford. Clarendon Press, pp. 51-79.

Larson, R and Segal, G. (1995) Knowledge of Meaning. Cambridge. MIT Press.

Lycan, W. (2000) Philosophy of Language. A Contemporary Introduction. London. Routledge

Lyons, J. (1968) Introduction to Theoretical Linguistics. Cambridge. Cambridge University Press.

Ndwiga, S. (2014) The Syntax and Pragmatics of the Gichuka Sentence: A Challenge to the Minimalist Program Analysis. Unpublished PhD Thesis. University of Nairobi.

Radford, A. (1997) Syntactic Theory and the Structure of English. A Minimalist Approach. Cambridge: Cambridge University Press.

Radford, A. (2004) English Syntax. An Introduction. Cambridge: Cambridge University Press.

Recanati, F. (1993) Direct Reference. From Language to Thought. Oxford: Blackwell.

Recanati, F. (2004) Literal Meaning. Cambridge. Cambridge University Press.

Sperber, D. and Wilson, D. (1986) Relevance: Communication and Cognition. Oxford: Basil Blackwell.

Steube, A., Alter, K. and Spath, A. (2004) Information structure and modular grammar. In Steube, A. (2004). Language, Context and Cognition. Information Structure. Theoretical and Empirical Aspects. Berlin: Walter de Gruyter, pp. 15-40. 